\title{
(In)Eficiência Educacional sob a Perspectiva dos Gastos Públicos Desagregados
}

\author{
Joyce Santana Bernardo' \\ Fernanda Maria de Almeida' \\ Ana Carolina Campana Nascimento' \\ 'Universidade Federal de Viçosa (UFV), Viçosa/MG - Brasil
}

RESUMO - (In)Eficiência Educacional sob a Perspectiva dos Gastos Públicos Desagregados. Para verificar a eficiência dos municípios brasileiros na aplicação dos recursos públicos desagregados na qualidade da educação pública, de 2009 a 2013, utilizou-se o método de Análise de Fronteira Estocástica, conforme Battese e Coelli (1995). Os resultados apontaram que aspectos sociais (gastos com saúde e infraestrutura) não foram propulsores da eficiência, apesar da maior destinação de recursos por parte dos mais eficientes. Dos gastos públicos educacionais desagregados, foram positivos os com infraestrutura, serviços terceirizados por pessoas jurídicas e com outras despesas. Ainda, os municípios mais eficientes foram os com menos alunos em sala de aula e, principalmente, com $90 \%$ dos alunos matriculados na série coerente à idade.

Palavras-chave: Qualidade da Educação. Eficiência. Gastos Públicos Desagregados. Fronteira Estocástica.

ABSTRACT - Educational (In)Efficiency from the Perspective of Disaggre-
gated Public Expenditures. To verify the efficiency of Brazilian municipali-
ties in the application of public resources disaggregated in the quality of
public education, from 2009 to 2013 , the Stochastic Frontier Analysis meth-
od was used, according to Battese and Coelli (1995). The results showed that
social aspects (health and infrastructure expenditures) were not drivers of
efficiency, despite the greater allocation of resources by the most efficient.
Of the disaggregated public educational expenditures, the infrastructure,
outsourced services by legal entities and other expenses were positive. In
addition, the most efficient municipalities were those with the fewest stu-
dents in the classroom and, especially, with $90 \%$ of the students enrolled in
the age-consistent grade. Keywords: Education Quality. Efficiency. Disaggregated Public Expenditures. Stochastic Frontier.

Educação \& Realidade, Porto Alegre, v. 46, n. 1, e105371, 2021. 1

http://dx.doi.org/10.1590/2175-6236105371 
(In)Eficiência Educacional sob a Perspectiva dos Gastos Públicos Desagregados

\section{Introdução}

A destinação e alocação de recursos públicos é orientada pelas necessidades detectadas pela Administração Pública e relatadas pela sociedade. Contudo, deve-se questionar se os recursos aplicados estão surtindo os efeitos desejados (eficaz) e/ou gerando o máximo de resultados possíveis (eficiente), em todas as dimensões econômicas e sociais.

A educação é um “[...] setor significativo em termos de despesas públicas e privadas e é uma política fundamental devido às suas ligações presumidas com capital humano, crescimento e inovação" (Grosskopf; Hayes; Taylor, 2014b, p. 20, tradução nossa). Contudo, Coleman et al. (1966) identificaram que níveis elevados de investimento educacional não geravam crescimento proporcional no desempenho dos alunos. Assim, políticas públicas para promoção, aprimoramento e eficiência na educação tornavam-se necessárias.

A eficiência educacional pode ser a relação entre tamanho da turma e desempenho escolar, tempo dedicado pelo professor por aluno; tamanho da escola e custos educacionais; entre outros, devendo considerar um mix de insumos neste processo. Pode também estar associada à qualidade do ensino (Delgado; Machado, 2008) e aos “[...] resultados observados da educação [...] produzidos no nível mais baixo de recursos" (Johnes; Portela; Thanassoulis, 2017, p. 331, tradução nossa). Outrossim, Zoghbi et al. (2011) ressaltaram a importância da eficiência educacional pois, assim, ocorreria desenvolvimento e crescimento econômico. Entretanto, para Savian e Bezerra (2013, p. 45) aqueles "[...] com melhor desempenho econômico não são necessariamente os mais eficientes”.

Na perspectiva internacional, Chakraborty (2009) e Grosskopf, Hayes e Taylor (2014a) analisaram distritos escolares nos Estados Unidos, para verificar a eficiência educacional. Encontraram expressiva ineficiência, cuja causa pode ser o tamanho das escolas (dados seus benefícios e dificuldades proporcionados pelo porte) e subutilização de colaboradores no processo educacional. Ademais, fatores socioeconômicos tiveram mais peso que insumos escolares.

No contexto brasileiro, Faria, Jannuzzi e Silva (2008) e Dalchiavon e Melo (2016) focaram na relação entre gastos públicos com educação e cultura; saúde e saneamento; e trabalho, com indicadores de condições de vida e desenvolvimento. Identificaram municípios positivos e negativos e, destacaram que um município pode gastar muito, de forma errônea, enquanto outro pode utilizar poucos recursos, mas, eficientemente, obtendo resultados melhores.

Também, Schuster e Zonatto (2017) identificaram a eficiência quanto à alocação de recursos agregados na educação dos dez maiores municípios brasileiros. Apontaram para nível de eficiência baixo e, que os mais eficientes gastaram menos, eram de pequeno porte e com baixa atividade econômica. Trigo (2010) analisou a eficiência das escolas brasileiras e a influência de variáveis ambientais (caracterizam a localidade do estudante) na ineficiência. Quanto mais alunos trabalhando concomitantemente aos estudos, maior a ineficiência escolar. Ainda, os 
atributos do corpo docente, a infraestrutura e dependência administrativa escolar, a proporção de alunos brancos e o grau de instrução das mães impactaram o desempenho escolar.

Enfatizando os municípios do Ceará, Gramani (2017, p. 521) utilizou aspectos relacionados a “[...] professores, qualidade da educação e fatores socioeconômicos que influenciam diretamente a educação (como renda, educação materna e acesso a esgoto sanitário)" e gasto escolar como resultado da análise de eficiência. Concluiu que o gasto, a renda per capita e a educação das mães impulsionaram a qualidade educacional.

A literatura deste tema é ampla, porém, os estudos mencionados não identificaram fatores influenciadores da educação, considerando a eficiência dos gastos educacionais desagregados. Neste contexto, objetiva-se verificar a eficiência dos municípios brasileiros quanto à aplicação dos recursos públicos desagregados e características sociais na qualidade da educação pública. Ademais, pretende-se identificar diferenças inter-regionais quanto à referida eficiência.

A realização deste trabalho é relevante por contribuir para a temática de eficiência educacional, pois permite entender o processo de produção da educação, e apontar os principais aspectos importantes na gestão eficiente dos recursos públicos desagregados. Ainda, contribui com a literatura ao identificar as regiões e estados com desenvolvimentos educacionais destoantes, permitindo, dessa forma, reflexões para adoção de ações para reduzir a desigualdade brasileira existente.

Este artigo é composto por cinco seções, sendo a primeira esta introdução, cujo intuito é contextualizar e apresentar a temática; a segunda aprofunda na revisão de literatura que aborda os conceitos de eficiência, com ênfase na Administração Pública e nos processos educacionais; a terceira contém os procedimentos metodológicos seguidos para operacionalizar o estudo; a quarta apresenta os resultados obtidos, realizando a discussão da prática com os aspectos teóricos e; a última seção traz as conclusões gerais alcançadas ao longo do trabalho.

\section{Eficiência na Administração Pública}

Dada a escassez dos recursos, as organizações devem buscar a alocação ótima destes para alcançar os objetivos definidos, prezando também pela qualidade. A utilização dos recursos depende de fatores como a tecnologia empregada e do próprio processo de produção (Ferreira; Gomes, 2012). Assim, atingir a eficiência na produção dos bens e serviços pode contribuir para o crescimento e desenvolvimento dessas organizações.

A eficiência pode ser técnica ou alocativa. A técnica orientada para o produto é a "[...] diferença entre o montante efetivamente produzido com certa quantidade de insumos e o montante factível de ser produzido, dada a tecnologia disponível”. Sob a ótica do insumo, é a “[...] diferença entre a quantidade de insumos efetivamente utilizada para 
(In)Eficiência Educacional sob a Perspectiva dos Gastos Públicos Desagregados

produzir determinado nível de produto e o montante mínimo factível de insumos necessários para produzir esse mesmo nível de produto com a tecnologia de produção disponível” (Mattos; Terra, 2015, p. 214). A eficiência alocativa está relacionada com a possibilidade de a organização produzir "[...] um mesmo nível que as demais de um dado conjunto de atividades, com o menor custo possível" (Ferreira; Gomes, 2012, p. 40). Ou seja, é utilizar de forma ótima os insumos, minimizando custos de produção.

Cada organização, mesmo com condições semelhantes, possui eficiências diferentes devido às maneiras de solucionar problemas e elaborar políticas. Conforme Fagerberg, Srholec e Verspagen (2009, p. 11), essa diferença existe por conta da congruência tecnológica e da capacidade social de cada ente federativo. A congruência tecnológica seria o “[...] grau em que as características do país líder e do país seguidor são congruentes em áreas como o tamanho do mercado, o fornecimento de fatores". As capacidades sociais são características que os municípios precisam desenvolver para recuperarem-se diante dos demais. A educação é um dos principais pilares para este avanço, atrelado à solidificação dos sistemas financeiro e comercial (Fagerberg et al., 2009).

Na Administração Pública existem modelos de gestão: patrimonial, burocrático e gerencial. O primeiro remonta à época imperial, onde o rei exercia sua vontade soberana, sem separação entre bens públicos (sociedade) e privados (rei) (Aguiar, 2000), atrelados às atitudes clientelistas. O burocrático pauta-se na distinção entre bens do governo e do governante, sistematização de processos para execução independente do governo e meritocracia, garantindo a inserção justa e igualitária no serviço público.

Além disso, o modelo gerencial respalda-se na escassez dos recursos públicos, sendo necessária atuação eficiente, para gerar bens e serviços de qualidade para a sociedade, empregando o mínimo possível de insumos. Essa forma de governo "[...] focaliza a flexibilidade de procedimentos e o maior controle dos resultados" (Seabra, 2001, p. 25). Há maior autonomia concedida aos administradores públicos, atrelada à maior necessidade de alcançar os resultados, tornando as informações sobre desempenho institucional mais transparentes (Pacheco, 2010).

Não obstante, a eficiência é princípio constitucional, pois “[...] a administração pública direta e indireta de qualquer dos Poderes da União, dos Estados, do Distrito Federal e dos Municípios obedecerá aos princípios de legalidade, impessoalidade, moralidade, publicidade e eficiência [...]" (Brasil, 1988, art.37). Ademais, a Lei de Responsabilidade Fiscal reforça a "[...] disseminação de práticas que resultem em maior eficiência na alocação e execução do gasto público, na arrecadação de receitas, no controle do endividamento e na transparência da gestão fiscal" (Brasil, 2000, art.67, II).

Percebe-se que os pressupostos para alcançar a eficiência estão presentes na legislação e nos modelos de gestão pública gerencial, utilizando mecanismos para alcançar os melhores resultados, com o mínimo de recursos possíveis. 


\section{Eficiência Educacional}

A educação está no cerne do desenvolvimento (Todaro; Smith, 2012) e, por isso, tem relevância nos estudos econômicos. Atrelada à demanda por mão de obra qualificada para compor o mercado de trabalho (Morais, 2009), e sob a égide da Teoria do Capital Humano, na qual melhores remunerações são recebidas por aqueles com maiores níveis de ensino (Andrade, 2010; Cabral; Silva; Silva, 2016), a oferta e obtenção de ensino de qualidade são constantemente necessárias.

Nesta ótica, Marginson (1991, p. 201, tradução nossa) afirma que a educação precisa "[...] expandir e melhorar a qualidade dos serviços, como mostra o rápido crescimento das matrículas no ensino médio, no treinamento e no ensino superior e as incessantes demandas para ampliar e aprofundar a gama de funções desempenhadas". Outrossim, emergiu o campo de estudos focados na eficiência educacional, pois não havia retornos crescentes e positivos dos alunos, ainda que houvesse dispêndios financeiros cada vez maiores (Levin; Jamison; Radner, 1976).

Assim, a economia da educação desenvolveu abordagens e modelos para compreender os fatores associados ao desempenho dos alunos. Neste sentido, surgiu a eficiência na alocação dos recursos em educação, composta por uma função de produção educacional. Levin, Jamison e Radner (1976) ilustram a eficiência na educação (Figura 1). A fronteira de produção educacional é representada pela isoquanta AoAo' e pelas observações individuais (escolas/municípios), resultantes das diversas combinações de insumos S1 e S2. Os pontos a, b e c são tecnicamente eficientes. Logo, sendo Z'Z o preço relativo (linha de restrição orçamentária), somente b é tecnicamente eficiente. Os pontos a e c deixam de ser eficientes, pois precisam de maiores aportes financeiros para alcançar o resultado Ao’.

Figura 1 - Fronteira de Produção Educacional

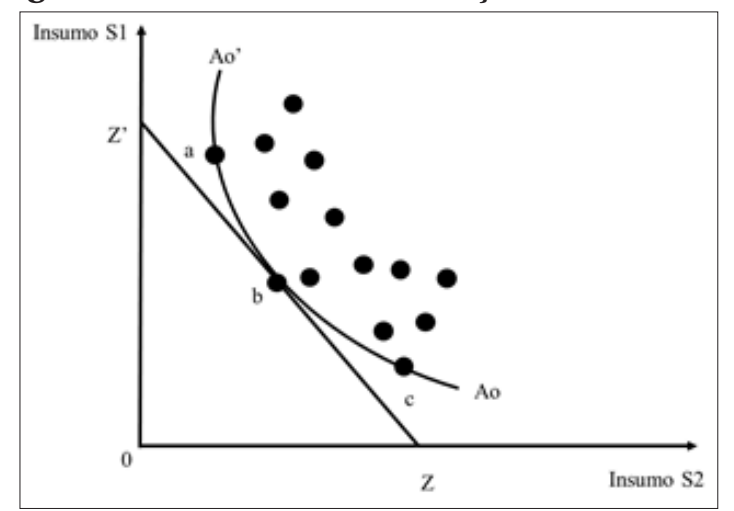

Fonte: Adaptado de Levin, Jamison e Radner (1976).

Os autores ainda consideraram o bem-estar social, sendo importante avaliar não somente a perspectiva técnica da alocação de recursos, 
mas também o atendimento às necessidades da sociedade beneficiada (ou não) pela execução das atividades relacionadas com o investimento analisado. Na Figura 2, a fronteira considera os pontos de eficiência da educação (E0, E1 e E2), dada a combinação de insumos que geram os produtos com as funções de satisfação da sociedade quanto aos resultados proporcionados pelas políticas educacionais ( $l 0$ e $l 1)$. Dessa forma,

\begin{abstract}
[...] dadas as possibilidades de produção e as preferências da comunidade, o nível mais alto de bem-estar é representado por E1[...]. É evidente que E0 dá à comunidade menos satisfação do que E1, mas o mais importante é que qualquer escolha de saídas dentro da parte sombreada do diagrama (por exemplo, E2) produzirá um nível de bemestar maior que E0. Ou seja, [...] pode ser melhor produzir ineficientemente aquilo que é altamente desejável para a comunidade do que produzir com perfeita eficiência aquilo que é de baixo valor (Levin et al., 1976, p. 155).
\end{abstract}

\title{
Figura 2 - Eficiência e Satisfação Social
}

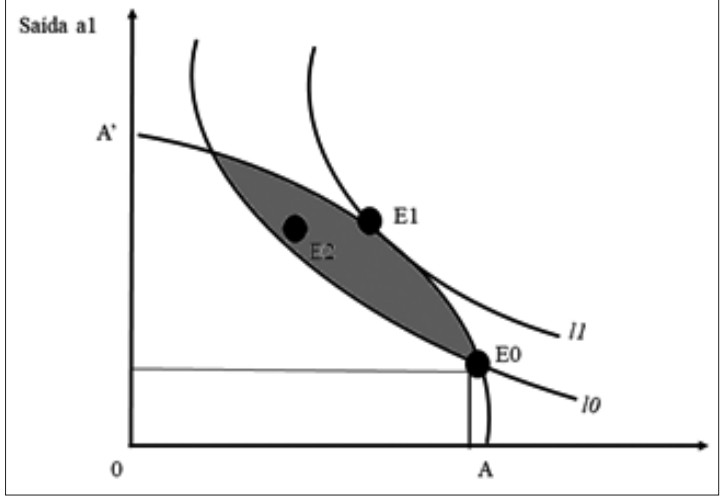

Fonte: Adaptado de Levin, Jamison e Radner (1976).

Neste contexto, é importante considerar insumos e produtos adequados para análise da eficiência, abarcando variáveis que representam com maior proximidade possível a realidade da educação brasileira. Ademais, a eficiência deve considerar as necessidades da população, visto ser importante o bem-estar social.

Na literatura, os principais propulsores da educação de qualidade são: relação entre aluno e professor (Urwick; Junaidu, 1991; Recuero; Olaberria, 2018); tamanho das turmas e escolas (Penkova; Valkov, 2015; Flores, 2017); gastos financeiros (Trigo, 2010; Zoghbi et al., 2011; Schuster; Zonatto, 2017); infraestrutura dos municípios, estados ou países (Carvalho; Waltenberg, 2015); desenvolvimento humano (Todaro; Smith, 2012); aspectos socioeconômicos (Penkova; Valkov, 2015); nutrição adequada dos estudantes (Ramos; Santos; Reis, 2013; Cunha, 2014); e background familiar (Silva; Hasenbalg, 2001; Morais, 2009). 


\section{Procedimentos Metodológicos}

Este estudo é descritivo e quantitativo. A amostra contemplou 4.642 municípios brasileiros em 2009, 4.635 em 2011 e 4.608 em 2013 (painel desbalanceado). O período analisado justifica-se pelo indicador de qualidade geral da educação básica municipal (IQGEM) utilizado estar disponível apenas para os anos mencionados (Bernardo; Almeida; Nascimento, 2020). A utilização de indicadores formais, como Índice de Desenvolvimento da Educação Básica (IDEB), contempla o desempenho do aluno e desconsidera aspectos externos influenciadores do resultado escolar. Assim, é relevante utilizar índices construídos com base em dimensões que impactam a aprendizagem, pois permite avaliar de forma mais abrangente a qualidade educacional. Dada a heterogeneidade entre as regiões, estados e, municípios brasileiros; ter estes últimos como unidades de análise contribuiu para compreender a eficiência na alocação de recursos públicos na educação, em nível desagregado.

A coleta dos dados deu-se nas plataformas: Sistema de Informações sobre Orçamentos Públicos em Educação (SIOPE), Instituto Brasileiro de Geografia e Estatística (IBGE), Instituto de Pesquisa Econômica Aplicada (IPEA), Departamento de Informática do Sistema Único de Saúde (DATASUS) e Secretaria do Tesouro Nacional (STN), entre outros.

\section{Variáveis e Tratamento Estatístico}

Utilizou-se o método de Fronteira Estocástica que, além da estimação dos índices de eficiência, possibilita identificar a contribuição de cada variável para o sistema educacional e considera a existência de dois componentes aleatórios. O primeiro é referente à ineficiência técnica e o segundo representa os erros aleatórios tradicionais. A Fronteira Estocástica com base na função de produção passou a incluir a existência do termo de erro composto: um com distribuição normal, e outro com distribuição unilateral normal (Aigner; Lovell; Schmidt, 1977).

Diante da necessidade de considerar as variações das unidades de análise $(i)$ ao longo do tempo $(t)$, Pitt e Lee (1981) e Schmidt e Sickles (1984) desenvolveram um modelo para dados em painel. Adicionalmente, Battese e Coelli (1995) construíram uma abordagem, onde "[...] os efeitos de ineficiência técnica são independentemente distribuídos (mas não identicamente)" (Pires, 2004, p. 39).

Conforme Battese e Coelli (1995, p. 326), a formulação geral da fronteira estocástica para dados em painel é:

$$
y_{i t}=\exp \left(x_{i t} \beta+v_{i t}-u_{i t}\right)(1)
$$

em que $y_{i t}$ representa valores do produto para i-ésima unidade de análise no t-ésimo período de tempo; $x_{i t}$ é matriz de insumos do processo de produção para i-ésima unidade de análise no período t-ésimo de tempo; $B$ e $\delta$ são vetores de parâmetros a estimar; $v_{i t}$ é termo aleatório "[...] distribuído de forma idêntica e independente $N\left(0, \sigma_{v}^{2}\right)$, além de distribuídos independentemente de $u_{i t}$; $u_{i t}$ são “[...] variáveis aleatórias não 
negativas, associadas à ineficiência técnica de produção, as quais são assumidas como distribuídas independentemente, de tal forma que são obtidas por truncamento (em zero) da distribuição normal com média, $z_{i t}$ e variância $\sigma^{2}$ " (Battese; Coelli, 1995, p. 326); $z_{i t}$ é vetor de variáveis explicativas da ineficiência técnica de produção das unidades ao longo do tempo.

Os parâmetros da Fronteira Estocástica são estimados por máxima verossimilhança, que considera "[...] como estimativas os valores dos parâmetros que tornam máximo o valor da função de verossimilhança. Isso é equivalente a encontrar o valor para o parâmetro que torna mínima a função de log-verossimilhança negativa” (Batista, 2009, p. 9).

Logo, a ineficiência técnica (Battese; Coelli, 1995) é:

$$
u_{i t}=\delta z_{i t}+w_{i t}(2)
$$

em que $u_{i t}$ representa efeitos de ineficiência técnica, assumidos independentes e identicamente distribuídos; $z_{i t}$ é vetor de variáveis explicativas da eficiência; $\delta$ é conjunto de parâmetros de cada $z_{i t}$; e $w_{i t}$ é "[...] uma variável aleatória com distribuição normal truncada com média zero e variância $\sigma_{u}^{2}$. Para que se comprove $u_{i t} \geq 0$ é necessário truncar $w_{i t}$ de modo a que $w_{i t} \geq-\delta z_{i t}$ (Bento, 2014, p. 45).

Então, a eficiência técnica $\left(T E_{i t}\right)$ (das unidades de análise é:

$$
T E_{i t}=\exp \left(-u_{i t}\right)=\exp \left(-z_{i t} \delta-w_{i t}\right)(3)
$$

Assim, as variáveis do modelo estão no Quadro 1, evidenciando as da função de relação produto-insumo (1) e as de ineficiência (2).

\begin{tabular}{|c|c|c|}
\hline Variável & Significado & Insumo/Produto \\
\hline IQGEM & $\begin{array}{l}\text { Índice de Qualidade Geral da Educação } \\
\text { Municipal }\end{array}$ & Produto \\
\hline Pessoal & \multirow{5}{*}{ Valor gasto, em ln, dividido pelas matrículas } & \multirow{5}{*}{ Insumos $X$} \\
\hline Material & & \\
\hline Despesas de Capital & & \\
\hline Outras despesas & & \\
\hline Serviços terceirizados & & \\
\hline $\begin{array}{l}\text { Mão de obra (MO) qua- } \\
\text { lificada }\end{array}$ & $\begin{array}{l}\text { Proporção de trabalhadores com ensino su- } \\
\text { perior sobre total de trabalhadores formais }\end{array}$ & \multirow{5}{*}{$\begin{array}{l}\text { Variáveis } Z \text { ex- } \\
\text { plicativas da (in) } \\
\text { eficiência }\end{array}$} \\
\hline Saúde & \multirow{2}{*}{$\begin{array}{l}\text { Gastos públicos municipais (em R\$/habi- } \\
\text { tante) }\end{array}$} & \\
\hline Infraestrutura & & \\
\hline Dummies estaduais & $\begin{array}{l}\text { Dummy que assume valor } 1 \text { quando municí- } \\
\text { pio i pertence ao estado; e zero caso contrário }\end{array}$ & \\
\hline Dummies de porte & $\begin{array}{l}\text { Dummies para porte municipal: pequeno } \\
\text { porte I até } 20.000 \text { habitantes, pequeno porte } \\
\text { II de } 20.001 \text { a } 50.000 \text {, médio porte entre } 50.001 \\
\text { e } 100.000 \text { e, grande porte acima de } 100.001\end{array}$ & \\
\hline
\end{tabular}

\section{Quadro 1 - Variáveis}

Fonte: Elaboração Própria. 


\section{Estatísticas Descritivas}

Na Tabela 1 estão as estatísticas descritivas das variáveis, dividindo-as em: financeiras (gastos desagregados com educação-R $\$ /$ matrícula), sociais (gastos com saúde e infraestrutura municipal-R $\$$ /habitante), educacionais (IQGEM e proporção de trabalhadores formais com ensino superior), regionais e de porte (dummies para considerar características não observáveis).

Tabela 1 - Estatísticas Descritivas

\begin{tabular}{lllllll}
\hline \multirow{2}{*}{ Variáveis } & $\mathbf{2 0 0 9}$ & & 2011 & \multicolumn{3}{c}{$\mathbf{2 0 1 3}$} \\
\cline { 2 - 7 } & Média & DP & Média & DP & Média & DP \\
\hline IQGEM & 0,610 & 0,17 & 0,614 & 0,16 & 0,604 & 0,17 \\
\hline $\begin{array}{l}\text { Vencimentos e vantagens } \\
\text { fixas }\end{array}$ & 785,57 & 310,37 & 973,84 & 375,06 & $1.159,43$ & 433,56 \\
\hline Obrigações patronais & 120,55 & 87,80 & 151,18 & 108,92 & 177,11 & 122,41 \\
\hline Outras despesas correntes & 540,72 & 294,13 & 655,31 & 352,65 & 669,73 & 363,09 \\
\hline Material Consumo & 223,72 & 167,41 & 286,22 & 201,50 & 293,38 & 211,36 \\
\hline Serviços PF & 69,01 & 97,00 & 67,03 & 100,81 & 39,46 & 74,36 \\
\hline Serviços PJ & 194,70 & 180,89 & 240,85 & 221,89 & 259,11 & 231,90 \\
\hline Despesas de Capital & 119,96 & 185,00 & 209,93 & 255,43 & 184,00 & 240,73 \\
\hline Gastos Saúde & 335,90 & 151,61 & 446,63 & 598,50 & 533,74 & 249,96 \\
\hline Gastos infraestrutura & 45,98 & 81,77 & 71,60 & 103,81 & 61,78 & 98,28 \\
\hline MO qualificada & 0,12 & 0,09 & 0,13 & 0,09 & 0,15 & 0,10 \\
\hline
\end{tabular}

Nota: variáveis monetárias deflacionadas pelo Índice de Preços ao Consumidor Amplo de 2009. Legenda: DP-desvio padrão.

Fonte: Dados da pesquisa.

Na Figura, 3 apresentam-se os valores desagregados investidos em educação, por matrícula no Brasil. A maior parte concentra-se na remuneração do pessoal envolvido direta (equipe escolar) e indiretamente (equipe administrativa) na manutenção e desenvolvimento do ensino. Em 2009, a média foi de R\$785,57 e em 2013, R\$1.159,43. Percebeu-se aumento desses gastos, possivelmente pela expansão das matrículas, pois esta exige a criação de novas instituições de ensino e aumento do quadro de pessoal.

As remunerações pagas aos servidores da educação aumentaram $48 \%$, entre 2009 e 2011. Ao criar novas escolas e/ou reduzir o tamanho das turmas, faz-se necessário ampliar a equipe escolar para atender às demandas locais. Pode-se explicar parcialmente este aumento devido ao crescente número de alunos com necessidades físicas e/ou cognitivas, que precisam de professores auxiliares, sendo direito do aluno especial ter auxílio para desenvolver atividades escolares (Brasil, 1996). 
Figura 3 - Gastos Educacionais Desagregados (R\$/matrícula)

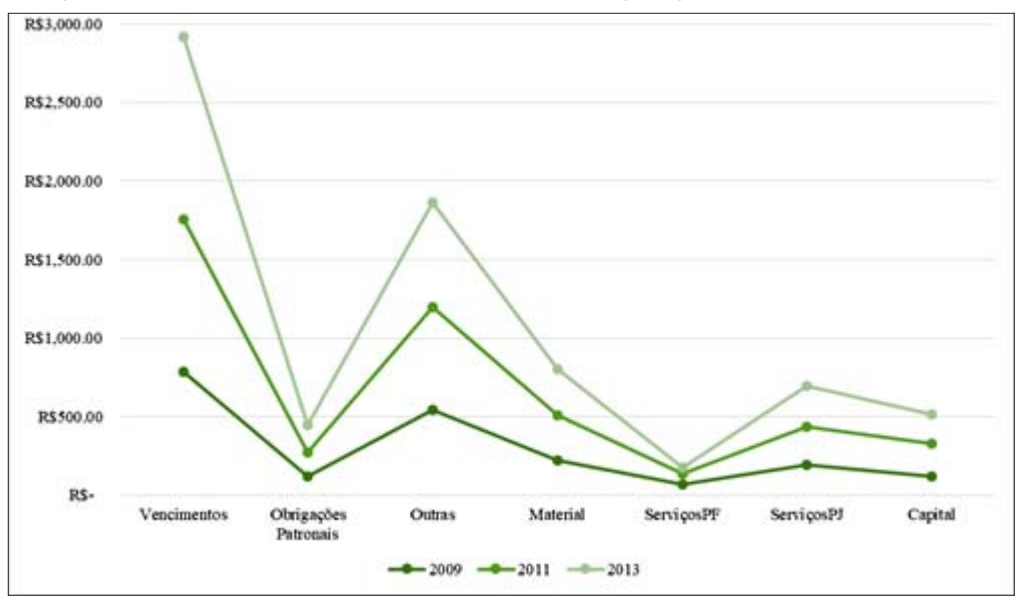

Fonte: Dados da Pesquisa.

Ainda, o item de despesa educacional Outras também foi crescente $(27,75 \%)$ entre 2009 e 2013. Nesta rubrica contábil estão alocados componentes necessários para promoção do ensino, tais como "[...] material de consumo, material de distribuição gratuita, passagens e despesas de locomoção, serviços de terceiros, locação de mão de obra, arrendamento mercantil, auxílio alimentação" (Senado Federal, 2018).

A Administração Pública precisa de prestadores terceirizados para garantir os direitos e cumprir com as obrigações inerentes a ela, tendo incorrido em redução de gastos com estes prestadores, na modalidade de pessoa física, em $47,86 \%$, e com o aumento de $33,39 \%$ com serviços prestados por pessoa jurídica. A instituição da Lei Complementar $n^{\circ}$ 128/2008 pode ter incentivado a criação de empresas como Microempreendedor Individual (MEI), obtendo tributação inferior, influenciando o aumento de empresas atendendo à Administração Pública.

Quanto às informações socioeconômicas, o gasto médio per capita com saúde e infraestrutura foi de $\mathrm{R} \$ 335,90$ e $\mathrm{R} \$ 45,98$, respectivamente, em 2009. Já em 2013, esses valores foram de $\mathrm{R} \$ 533,74$ (saúde) e $\mathrm{R} \$ 61,78$ (infraestrutura). Notou-se aumento médio de $34,36 \%$ na dimensão de infraestrutura e $58,90 \%$ dos gastos na saúde, corroborando Vieira (2018, p. 11), “[...] o gasto do SUS com medicamentos nas três esferas de governo passou, em termos reais, de $\mathrm{R} \$ 14,3$ bilhões em 2010 para quase R \$20 bilhões em 2015 (crescimento de 40\%)".

Quanto à proporção de trabalhadores formais com ensino superior, houve aumento de três pontos percentuais, indicando a busca por profissionalização e formação educacional. O intuito de obter maiores níveis de escolarização é alcançar, consequentemente, cargos e salários elevados, condizentes com a formação (Ide; Rotta Junior, 2013; Cabral; Silva; Silva, 2016). 


\section{Fronteira Estocástica}

Os coeficientes estimados pela fronteira estocástica e os testes da estimação, evidenciando os efeitos dos gastos educacionais desagregados (insumos) no IQGEM (produto), estão na Tabela 2. Conforme estatística de Wald, o modelo é estatisticamente significativo com 99\% de confiança.

Tabela 2 - Eficiência pela Fronteira Estocástica

\begin{tabular}{|c|c|c|}
\hline & Variáveis & Estimativas \\
\hline \multirow{8}{*}{ Insumos X } & (ln)Vencimentos e vantagens fixas & $\begin{array}{l}0,0017 \\
(0,0028) \mathrm{ns}\end{array}$ \\
\hline & (ln)Obrigações patronais & $\begin{array}{l}-0,0013 \\
(0,0008) \mathrm{ns}\end{array}$ \\
\hline & (ln)Outras despesas correntes & $\begin{array}{l}0,0723 \\
(0,0043)^{* * *}\end{array}$ \\
\hline & (ln)Material Consumo & $\begin{array}{l}-0,0026 \\
(0,0023) \mathrm{ns}\end{array}$ \\
\hline & (ln)ServiçosPF & $\begin{array}{l}-0,0102 \\
(0,0006)^{* * *}\end{array}$ \\
\hline & (ln)ServiçosPJ & $\begin{array}{l}0,0049 \\
(0,0018)^{* * *}\end{array}$ \\
\hline & (ln)Despesas de Capital & $\begin{array}{l}0,0076 \\
(0,0007)^{* * *}\end{array}$ \\
\hline & Constante & $\begin{array}{l}0,2373 \\
(0,0184)^{* * *}\end{array}$ \\
\hline & Wald & $1.573,97$ \\
\hline & Prob $>$ chi $^{2}$ & 0,0000 \\
\hline & LL & $8.918,25$ \\
\hline
\end{tabular}

Nota: em parênteses estão os erros padrão dos coeficientes. ${ }^{*},{ }^{* *}, * * *$ e ns significam, respectivamente, 90\%, 95\%, 99\% de confiança e sem significância. Fonte: Dados da pesquisa.

Sobre os gastos educacionais desagregados e suas relações com o IQGEM, as despesas com remuneração de pessoal, obrigações patronais e materiais de consumo não foram significativas estatisticamente. Dado que os tributos recolhidos com folhas de pagamento não são voltados exclusivamente para o financiamento educacional, é plausível que esta rubrica não interfira na qualidade desta.

Contudo, os materiais de consumo são insumos básicos para promover o ensino, porém, ao analisar os municípios brasileiros, é comum que alguns tenham dificuldade no fornecimento de itens essenciais, como giz, folhas de papel, entre outros. Assim, essa variável, por ter valores irrisórios, na média, não interferiu na qualidade da educação. Tal fato pode se dar devido ao grande número de municípios com baixo investimento, não possibilitando a identificação exata do efeito no IQGEM.

Já a ausência de significância das despesas com a remuneração aos profissionais pode se dar ao efeito cumulativo dos impactos educa- 
(In)Eficiência Educacional sob a Perspectiva dos Gastos Públicos Desagregados

cionais, ou seja, os investimentos do período corrente poderão trazer benefícios nos índices de avaliação em períodos posteriores (Schuster; Zonatto, 2017). Ademais, acredita-se que os possíveis efeitos diretos proporcionados pelos professores sejam baixos, considerando os municípios, os períodos e o modelo adotado. Ainda, é possível que os salários pagos a outros servidores estejam omitindo parte dos benefícios proporcionados pelos professores, pois as equipes auxiliares não possuem o contato diário direto em sala de aula com os estudantes.

Adicionalmente, dada a falta de treinamento dos gestores, representada pela dependência da gestão pública pelos softwares contábeis que elaboram a prestação de contas municipais (Sediyama; Aquino; Lopes, 2017), itens de grande peso para alavancar a educação municipal podem ter sido contabilizados indevidamente, explicando a ausência de significância estatística das demais variáveis financeiras, assim como ocorreu com as despesas com obrigações patronais, que podem ser importantes para aumentar a eficiência educacional (mas não tiveram esse efeito neste estudo).

As demais despesas mostraram-se importantes no processo de produção educacional com confiança de 99\%. Nas Despesas de Capital, por exemplo, encontram-se as obras, manutenções nas edificações, reformas e expansões. O efeito positivo é justificável, porquanto é necessário local apropriado para os estudantes absorverem os conteúdos lecionados (Penkova; Valkov, 2015). As Outras despesas também impulsionaram a qualidade educacional, pois nesta estão alocados diversos itens (auxílios, materiais de consumo, alimentação). Logo, o investimento em componentes que propiciam ambiente adequado para ensinar e aprender, pode aumentar o desempenho escolar (Sousa Junior, 2009).

Corroborando, as despesas com terceirização de pessoas jurídicas foram positivas no IQGEM. Conforme Penkova e Valkov (2015) e Masi (2018), estes componentes tendem a impulsionar a qualidade educacional, pois são insumos para a promoção e desenvolvimento do ensino. Entretanto, os gastos com terceirização de pessoas físicas foram negativos. A ausência ou deficiência nas fiscalizações dos contratos firmados entre pessoas e a Administração Pública (Almeida, 2009) pode ser motivo para este resultado, pois na falta de fiscalização, os serviços contratados podem não ser efetivamente prestados ou, ainda, prestados com qualidade inferior ao acordado. Como consequência, pode haver interferência no desempenho dos estudantes, que dependem de insumos escolares.

Posterior à estimação da função de fronteira estocástica, estimou-se os escores de eficiência para cada município em cada período de tempo, sendo ilustrado no mapa o escore médio (Figura 4). As eficiências médias foram $69,64 \%$ (2009), 71,80\% (2011) e 72,70\% (2013). Notou-se um crescimento no investimento em educação e melhorias na qualidade desta. Em 2009, 2011 e 2013, 55,73\%, 52,00\% e 51,26\% dos municípios, respectivamente, ficaram com escore inferior à média. E $44,27 \%, 48,00 \%$ e 48,74\% dos municípios tiveram eficiências superiores às médias dos anos analisados. 
Figura 4 - Eficiência Média Educacional dos Municípios entre 2009 e 2013

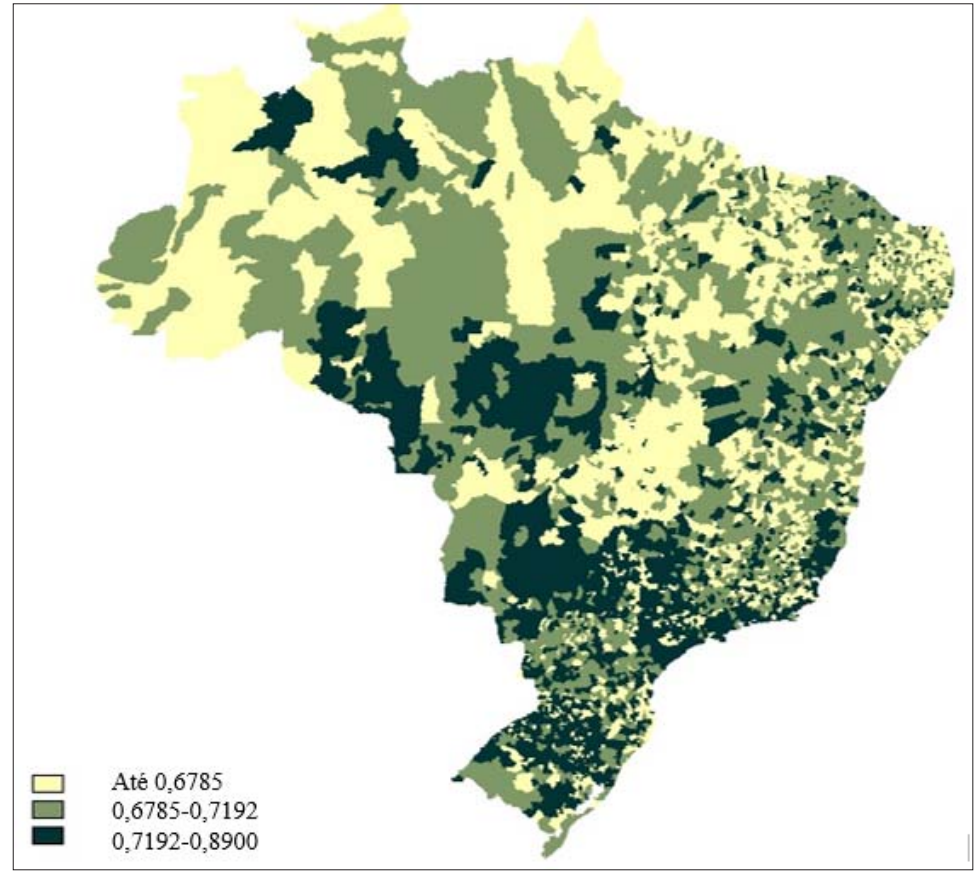

Fonte: Dados da Pesquisa.

De modo geral, Sul e Sudeste foram as regiões mais eficientes, além do Ceará, que tem registrado, desde 2007, avanços e melhorias na educação, resultado de políticas públicas elaboradas pelo estado e municípios, como Sobral, cujo IDEB “[...] era de 4,0, em 2005 (anos iniciais), em 2013, alcançou a nota 7,8, superando consideravelmente a meta estipulada pelo governo [...] a experiência de Sobral foi recomendada para todo o país como um exemplo de sucesso e boas práticas educacionais" (Gramani, 2017, p. 510).

\section{Aspectos Inter-Relacionais da Eficiência}

Para ilustrar características sociais e educacionais dos municípios com eficiência semelhantes construíram-se as Tabelas 3 (dez municípios mais eficientes de cada ano) e 4 (dez mais ineficientes). O primeiro ponto levantado é a localização, estando os mais eficientes no Sul e Sudeste, exceto São Francisco do Condé (BA) e os menos eficientes nos estados nortistas e nordestinos, majoritariamente.

Nos mais eficientes, as Taxas Distorção Idade-Série (TDI) foram mais baixas, variando de $5,95 \%$ a $41,50 \%$, enquanto nos ineficientes foi entre $21,50 \%$ e $64,80 \%$. Assim, naqueles menos eficientes, a TDI foi 3,6 vezes maior que nos mais eficientes, sinalizando a significativa im- 
portância das características intraescolares para o bom andamento da qualidade educacional.

Ademais, as taxas de aprovação nos mais ineficientes tiveram o mínimo (60,70\%) bem próximo do estabelecido no Brasil para que o aluno avance as séries/modalidades (60\%), e o máximo de $91,70 \%$, além de taxa de abandono entre $1,70 \%$ e $25,80 \%$. Contudo, nos mais eficientes há altos níveis de aprovação (72,60\%-100\%) e baixas taxas de abandono $(0 \%-10,70 \%)$. Ainda, naqueles mais eficientes há uma média de 14 a 25 alunos/turma, reforçando a importância de turmas menores, para que os professores consigam adequar as metodologias didático-pedagógicas para atender as especificidades dos estudantes (Pintoco, 2017).

Os mais eficientes são majoritariamente de pequeno porte, sendo que 18 não ultrapassam 10 mil habitantes. Destes, o com maior número de matrículas possui pouco mais de 800 alunos. Entretanto, os que tiveram escores menores foram diversificados, tendo municípios de pequeno porte I (14), pequeno porte II (11), médio porte (3) e grande porte (2). Portanto, o porte populacional não foi determinante da eficiência naqueles com dificuldades de gestão eficiente.

Diante disso, reflete-se sobre as discrepâncias nos valores investidos, pois nos mais eficientes os valores médios per capita gastos com saúde variaram de $\mathrm{R} \$ 382,17$ a $\mathrm{R} \$ 3.466,69$. Por outro lado, nos menos eficientes, localizados majoritariamente no Norte e Nordeste, o valor mínimo foi de $\mathrm{R} \$ 154,03$ e o máximo de $\mathrm{R} \$ 665,07$, podendo ser reflexo das dificuldades destas regiões em ofertar serviços públicos essenciais para a população, como o acesso à saúde de qualidade. 
Bernardo; Almeida; Nascimento

\section{Tabela 3 - Municípios Mais Eficientes}

\begin{tabular}{|c|c|c|c|c|c|c|c|c|c|c|c|c|}
\hline $\begin{array}{l}\text { Ran } \\
\text { king }\end{array}$ & Município & Ano & EFI & $\begin{array}{l}\text { IQ- } \\
\text { GEM }\end{array}$ & MAT & POP & TDI & APT & APR & $\mathrm{AB}$ & GS & GI \\
\hline $1^{\circ}$ & $\begin{array}{l}\text { BOA VISTA DO } \\
\text { CADEADO-RS }\end{array}$ & 2009 & 0,87 & 0,75 & 446 & 2525 & 18,45 & 16,87 & 79,70 & 0,30 & 699,14 & 7,16 \\
\hline $2^{\circ}$ & $\begin{array}{l}\text { SANTA SALETE- } \\
\text { SP }\end{array}$ & & 0,87 & 0,97 & 285 & 1446 & 8,40 & 16,80 & 99,20 & 0,00 & 873,47 & 366,09 \\
\hline $3^{\circ}$ & $\begin{array}{l}\text { SEBASTIANOPO- } \\
\text { LIS DO SUL-SP }\end{array}$ & & 0,86 & 0,94 & 606 & 3109 & 8,90 & 21,33 & 97,55 & 0,00 & 781,44 & 196,21 \\
\hline $4^{\circ}$ & $\begin{array}{l}\text { NOVA CASTI- } \\
\text { LHO-SP }\end{array}$ & & 0,86 & 0,85 & 257 & 1122 & 14,20 & 19,00 & 87,80 & 0,00 & 1187,34 & 175,03 \\
\hline $5^{\circ}$ & UBATUBA-SP & & 0,85 & 0,79 & 21142 & 81096 & 14,30 & 25,10 & 88,15 & 1,45 & 382,17 & 14,55 \\
\hline $6^{\circ}$ & $\begin{array}{l}\text { BOA VISTA DO } \\
\text { INCRA-RS }\end{array}$ & & 0,85 & 0,77 & 502 & 2583 & 20,65 & 14,23 & 84,30 & 0,75 & 642,36 & 0,01 \\
\hline $7^{\circ}$ & TRIUNFO-RS & & 0,84 & 0,63 & 7098 & 25374 & 32,10 & 21,17 & 80,60 & 10,70 & 469,42 & 165,75 \\
\hline $8^{\circ}$ & PORTO REAL-RJ & & 0,84 & 0,67 & 3795 & 16253 & 29,35 & 21,10 & 80,10 & 0,75 & 1487,84 & 117,78 \\
\hline $9^{\circ}$ & $\begin{array}{l}\text { ITAIPULANDIA- } \\
\text { PR }\end{array}$ & & 0,84 & 0,68 & 2237 & 9349 & 31,50 & 24,17 & 80,85 & 3,65 & 795,91 & 45,21 \\
\hline $10^{\circ}$ & $\begin{array}{l}\text { P R E S I DE N T E } \\
\text { KENNEDY-ES }\end{array}$ & & 0,84 & 0,55 & 2659 & 10903 & 34,45 & 19,77 & 72,60 & 5,30 & 1021,28 & 93,66 \\
\hline $1^{\circ}$ & $\begin{array}{l}\text { P R E S I DE N T E } \\
\text { KENNEDY-ES }\end{array}$ & 2011 & 0,93 & 0,61 & 3005 & 10373 & 30,45 & 19,17 & 80,45 & 7,95 & 1760,00 & 126,52 \\
\hline $2^{\circ}$ & $\begin{array}{l}\text { NOVA CASTI- } \\
\text { LHO-SP }\end{array}$ & & 0,89 & 0,87 & 256 & 1136 & 9,90 & 15,93 & 93,05 & 2,45 & 1643,27 & 982,18 \\
\hline $3^{\circ}$ & PORTO REAL-RJ & & 0,89 & 0,65 & 3788 & 16938 & 29,90 & 21,77 & 80,35 & 4,50 & 2412,95 & 962,69 \\
\hline $4^{\circ}$ & $\begin{array}{l}\text { SEBASTIANOPO- } \\
\text { LIS DO SUL-SP }\end{array}$ & & 0,88 & 0,92 & 557 & 3069 & 8,20 & 19,50 & 97,90 & 0,80 & 992,40 & 115,78 \\
\hline $5^{\circ}$ & $\begin{array}{l}\text { SERRA DA SAU- } \\
\text { DADE-MG }\end{array}$ & & 0,86 & 0,69 & 163 & 811 & 13,1 & 10,90 & 100 & 0 & 1821,73 & 785,78 \\
\hline $6^{\circ}$ & $\begin{array}{l}\text { SANTA SALETE- } \\
\text { SP }\end{array}$ & & 0,86 & 0,79 & 301 & 1453 & 6,75 & 15,47 & 97,95 & 0,60 & 1093,60 & 13,66 \\
\hline $7^{\circ}$ & CUBATAO-SP & & 0,86 & 0,71 & 30762 & 119520 & 24,35 & 26,60 & 84,30 & 3,50 & 1309,92 & 15,49 \\
\hline $8^{\circ}$ & MERIDIANO-SP & & 0,85 & 0,87 & 804 & 3842 & 8,10 & 19,93 & 89,05 & 5,55 & 689,20 & 606,91 \\
\hline $9^{\circ}$ & $\begin{array}{l}\text { SAO FRANCISCO } \\
\text { DO CONDE-BA }\end{array}$ & & 0,85 & 0,47 & 9670 & 33713 & 41,50 & 25,07 & 77,15 & 9,80 & 428,54 & 461,54 \\
\hline $10^{\circ}$ & ANHEMBI-SP & & 0,85 & 0,80 & 1494 & 5739 & 13,25 & 21,83 & 92,30 & 0,30 & 714,73 & 272,27 \\
\hline $1^{\circ}$ & $\begin{array}{l}\text { P R E S I DE N T E } \\
\text { KENNEDY-ES }\end{array}$ & 2013 & 0,91 & 0,51 & 2770 & 11130 & 32,95 & 18,73 & 75,50 & 9,95 & 0,00 & 0,00 \\
\hline $2^{\circ}$ & $\begin{array}{l}\text { SAO GONCALO } \\
\text { DO RIO ABAIXO- } \\
\text { MG }\end{array}$ & & 0,89 & 0,70 & 2459 & 10384 & 24,65 & 22,73 & 86,80 & 6,85 & 2594,15 & 143,24 \\
\hline $3^{\circ}$ & $\begin{array}{l}\text { SEBASTIANOPO- } \\
\text { LIS DO SUL-SP }\end{array}$ & & 0,87 & 0,87 & 616 & 3252 & 9,45 & 21,77 & 96,35 & 2,20 & 1148,30 & 127,72 \\
\hline $4^{\circ}$ & PORTO REAL-RJ & & 0,87 & 0,63 & 3937 & 17663 & 27,45 & 22,57 & 84,80 & 3,80 & 3466,69 & 221,21 \\
\hline $5^{\circ}$ & $\begin{array}{l}\text { BOA VISTA DO } \\
\text { CADEADO-RS }\end{array}$ & & 0,87 & 0,80 & 431 & 2520 & 19,35 & 17,17 & 95,65 & 0,85 & 0,00 & 0,00 \\
\hline $6^{\circ}$ & BALBINOS-SP & & 0,87 & 0,83 & 250 & 4433 & 5,95 & 14,07 & 99,05 & 0,95 & 707,47 & 73,54 \\
\hline $7^{\circ}$ & CUBATÃO-SP & & 0,86 & 0,68 & 30703 & 125178 & 22,15 & 24,43 & 82,15 & 3,25 & 1408,74 & 0,00 \\
\hline $8^{\circ}$ & MARAPOAMA-SP & & 0,86 & 0,90 & 536 & 2818 & 13,30 & 16,20 & 94,05 & 2,20 & 841,66 & 0,00 \\
\hline $9^{\circ}$ & DIRCE REIS-SP & & 0,86 & 0,87 & 301 & 1760 & 7,65 & 16,63 & 92,80 & 0,00 & 1260,56 & 308,53 \\
\hline $10^{\circ}$ & BURITIZAL-SP & & 0,86 & 0,60 & 806 & 4279 & 36,45 & 19,07 & 85,45 & 5,60 & 1004,42 & 213,37 \\
\hline
\end{tabular}

Legenda: EFI-Eficiência; IQGEM-Índice de Qualidade Geral da Educação Municipal; MAT-número de matrículas; POP-população; TDI-Taxa de Distorção Idade-Série; APTAlunos Por Turma; APR-Taxa de Aprovação; AB-Taxa de Abandono; MD-Matrículas por Docente; GS-Gastos com Saúde; GI-Gastos com Infraestrutura. Fonte: Dados da pesquisa. 
$\underline{\text { (In)Eficiência Educacional sob a Perspectiva dos Gastos Públicos Desagregados }}$

Tabela 4 - Municípios Menos Eficientes

\begin{tabular}{|c|c|c|c|c|c|c|c|c|c|c|c|c|}
\hline $\begin{array}{l}\text { Ran } \\
\text { king }\end{array}$ & Município & Ano & EFI & IQGEM & MAT & POP & TDI & APT & APR & $\mathrm{AB}$ & GS & GI \\
\hline $1^{\circ}$ & MIRANDIBA-PE & 2009 & 0,54 & 0,59 & 4238 & 13810 & 38,05 & 26,37 & 90,55 & 2,15 & 269,77 & 52,57 \\
\hline $2^{\circ}$ & ITAPORANGA-PB & & 0,55 & 0,46 & 6274 & 23224 & 30,75 & 22,97 & 78,35 & 13,10 & 222,96 & 47,36 \\
\hline $3^{\circ}$ & OIAPOQUE-AP & & 0,55 & 0,44 & 7443 & 20962 & 53,30 & 22,50 & 77,00 & 12,25 & 171,32 & 46,42 \\
\hline $4^{\circ}$ & UIRAUNA-PB & & 0,56 & 0,47 & 3726 & 14963 & 35,65 & 19,80 & 78,60 & 14,30 & 190,60 & 42,59 \\
\hline $5^{\circ}$ & LIMOEIRO-PE & & 0,56 & 0,63 & 16450 & 57243 & 33,85 & 24,13 & 84,70 & 4,75 & 210,08 & 48,98 \\
\hline $6^{\circ}$ & LENCOIS-BA & & 0,56 & 0,43 & 3021 & 10112 & 47,60 & 19,87 & 69,30 & 10,80 & 245,26 & 0,00 \\
\hline $7^{\circ}$ & $\begin{array}{l}\text { CRUZEIRO DO SUL- } \\
\text { AC }\end{array}$ & & 0,57 & 0,61 & 28359 & 77004 & 29,80 & 25,37 & 81,70 & 8,65 & 154,03 & 17,76 \\
\hline $8^{\circ}$ & $\begin{array}{l}\text { AURORA DO PARA- } \\
\text { PA }\end{array}$ & & 0,57 & 0,16 & 7521 & 22315 & 64,80 & 22,73 & 60,70 & 25,80 & 0,00 & 41,15 \\
\hline $9^{\circ}$ & PARELHAS-RN & & 0,57 & 0,53 & 5423 & 20676 & 33,85 & 25,77 & 78,50 & 12,25 & 283,60 & 0,00 \\
\hline $10^{\circ}$ & $\begin{array}{l}\text { SANTANA DO SAO } \\
\text { FRANCISCO-SE }\end{array}$ & & 0,57 & 0,34 & 2389 & 6861 & 44,30 & 26,33 & 70,55 & 14,05 & 366,76 & 13,98 \\
\hline $1^{\circ}$ & SAO CRISTOVÃO-SE & 2011 & 0,47 & 0,38 & 19024 & 79956 & 44,70 & 25,13 & 71,25 & 10,10 & 167,48 & 7,02 \\
\hline $2^{\circ}$ & PARELHAS-RN & & 0,55 & 0,47 & 5487 & 20434 & 36,70 & 24,87 & 76,95 & 13,95 & 318,36 & 0,00 \\
\hline $3^{\circ}$ & VITORIADOJARI-AP & & 0,56 & 0,41 & 4494 & 12725 & 46,85 & 22,70 & 72,50 & 10,60 & 332,23 & 166,85 \\
\hline $4^{\circ}$ & $\begin{array}{l}\text { GLORIA DE DOURA- } \\
\text { DOS-MS }\end{array}$ & & 0,57 & 0,65 & 2126 & 9919 & 27,30 & 20,03 & 82,10 & 6,35 & 430,27 & 283,10 \\
\hline $5^{\circ}$ & BARBACENA-MG & & 0,58 & 0,79 & 28298 & 127218 & 21,50 & 24,03 & 87,80 & 1,70 & 665,07 & 8,18 \\
\hline $6^{\circ}$ & $\begin{array}{l}\text { SANTA MARIA DAS } \\
\text { BARREIRAS-PA }\end{array}$ & & 0,58 & 0,43 & 4480 & 17686 & 56,55 & 17,77 & 87,85 & 6,30 & 196,62 & 1,29 \\
\hline $7^{\circ}$ & OIAPOQUE-AP & & 0,59 & 0,45 & 7354 & 21095 & 51,80 & 20,90 & 77,50 & 10,85 & 216,76 & 85,41 \\
\hline $8^{\circ}$ & PROPRIA-SE & & 0,59 & 0,48 & 8585 & 28533 & 33,35 & 24,63 & 78,60 & 10,60 & 309,08 & 0,00 \\
\hline $9^{\circ}$ & SATUBA-AL & & 0,59 & 0,43 & 4115 & 14815 & 36,60 & 26,70 & 74,55 & 9,70 & 274,34 & 0,00 \\
\hline $10^{\circ}$ & BELEM-AL & & 0,59 & 0,40 & 1625 & 4446 & 49,50 & 20,53 & 74,65 & 9,30 & 545,53 & 5,78 \\
\hline $1^{\circ}$ & AMAPA-AP & 2013 & 0,58 & 0,34 & 2873 & 8483 & 42,90 & 21,37 & 76,85 & 13,50 & 311,60 & 0,00 \\
\hline $2^{\circ}$ & $\begin{array}{l}\text { CURRAIS NOVOS- } \\
\text { RN }\end{array}$ & & 0,58 & 0,62 & 10573 & 44528 & 24,60 & 23,93 & 85,20 & 5,05 & 305,18 & 3,79 \\
\hline $3^{\circ}$ & ESPUMOSO-RS & & 0,59 & 0,74 & 3140 & 15770 & 21,80 & 17,07 & 81,80 & 4,70 & 379,99 & 12,00 \\
\hline $4^{\circ}$ & SANTANA-AP & & 0,59 & 0,57 & 31374 & 108897 & 26,20 & 23,87 & 84,25 & 6,20 & 218,13 & 9,26 \\
\hline $5^{\circ}$ & PEDRINHAS-SE & & 0,60 & 0,45 & 2610 & 9298 & 37,25 & 25,67 & 84,45 & 1,90 & 303,41 & 0,00 \\
\hline $6^{\circ}$ & PATU-RN & & 0,60 & 0,38 & 2879 & 12561 & 41,00 & 22,43 & 79,60 & 11,65 & 454,09 & 12,41 \\
\hline $7^{\circ}$ & NOVA CRUZ-RN & & 0,60 & 0,26 & 10468 & 37079 & 39,00 & 26,70 & 75,25 & 14,65 & 199,37 & 23,10 \\
\hline $8^{\circ}$ & XAPURI-AC & & 0,61 & 0,56 & 4694 & 17021 & 34,35 & 21,03 & 85,50 & 4,50 & 273,09 & 55,15 \\
\hline $9^{\circ}$ & TAIOBEIRAS-MG & & 0,61 & 0,71 & 8239 & 32698 & 22,40 & 25,47 & 91,70 & 3,00 & 575,21 & 95,22 \\
\hline $10^{\circ}$ & QUIJINGUE-BA & & 0,61 & 0,42 & 7777 & 28996 & 40,95 & 25,33 & 83,95 & 4,80 & 316,21 & 92,68 \\
\hline \multicolumn{13}{|c|}{$\begin{array}{l}\text { Legenda: Legenda: EFI-Eficiência; IQGEM-Índice de Qu } \\
\text { Municipal; MAT-número de matrículas; POP-populaç } \\
\text { Idade-Série; APT-Alunos Por Turma; APR-Taxa de } \\
\text { Abandono; MD-Matrículas por Docente; GS-Gastos cc } \\
\text { Infraestrutura. } \\
\text { Fonte: Dados da pesquisa. }\end{array}$} \\
\hline
\end{tabular}

16 Educação \& Realidade, Porto Alegre, v. 46, n. 1, e105371, 2021. 
Na infraestrutura, tal comportamento foi semelhante. Dos $30 \mathrm{mu}$ nicípios menos eficientes, 18 investiram abaixo de $\mathrm{R} \$ 25,00$ por habitante, tendo um município com 17.686 habitantes investido apenas $\mathrm{R} \$ 1,29$ per capita. Enquanto somente dois investiram acima de $\mathrm{R} \$ 150,00$. Com relação aos mais eficientes, o menor investimento foi de $\mathrm{R} \$ 0,01$ indo até o máximo de R\$982,18, num município de apenas 1.136 habitantes.

Em suma, pode-se verificar que as regiões Norte e Nordeste possuem deficiências que interferem no alcance de eficiências maiores, resultantes de fatores regionais, econômicos e institucionais. Dentre as exceções estão Vitória do Xingu (PA) e São Francisco do Conde (BA), com $84 \%$ e $85 \%$ de eficiência na alocação dos recursos públicos, respectivamente. Estes municípios buscam constantemente melhorias na educação, especialmente devido ao crescimento nas notas do IDEB ao longo dos anos. Os municípios menores, em termos populacionais e com maiores investimentos em saúde e infraestrutura conseguiram se destacar para prover o desenvolvimento educacional.

\section{Determinantes da Ineficiência Educacional}

Na Tabela 5 apresentam-se os resultados obtidos com estimação da função de ineficiência (2), com a contribuição (ou não) de variáveis sociais, econômicas, e aspectos de regionalização na ineficiência do processo de produção educacional (determinantes da ineficiência-Z). Os coeficientes positivos indicam aumento da ineficiência, enquanto os negativos, diminuição da ineficiência (aumento da eficiência técnica) (Battese; Coelli, 1995).

Quanto aos termos de erro da função de Battese e Coelli (1995), notou-se ineficiência quanto à utilização dos gastos para gerar educação de qualidade, em torno de $12,75 \%$ (Sigma_u). Os erros aleatórios percebidos nos municípios foram apenas 8,35\% (Sigma_v). Ou seja, durante a alocação dos gastos públicos educacionais, houve ineficiência de $12,75 \%$, resultado este que poderia gerar efeitos positivos maiores, caso os recursos fossem bem geridos, reforçando as dificuldades dos administradores públicos na gestão dos recursos para obter qualidade educacional com eficiência (Grosskopf et al., 2014b; Schuster; Zonatto, 2017).

Tabela 5 - Resultados da Função de Ineficiência

\begin{tabular}{l|l}
\hline Variáveis & Estimativas \\
\hline (ln)Gastos Saúde & $\begin{array}{l}1,7127 \\
(0,0985)^{* * *}\end{array}$ \\
\hline (ln)Gastos Saúde(t-1) & $\begin{array}{l}0,0636 \\
(0,0588) \mathrm{ns}\end{array}$ \\
\hline \multirow{2}{*}{ (ln)Gastos Infraestrutura } & $\begin{array}{l}0,0208 \\
(0,0152) \mathrm{ns}\end{array}$ \\
\hline \multirow{2}{*}{ MO qualificada } & $\begin{array}{l}1,4366 \\
(0,2552)^{* * *}\end{array}$ \\
\hline \multirow{2}{*}{ AC } & $\begin{array}{l}-0,1897 \\
(0,7558) \mathrm{ns}\end{array}$ \\
\hline
\end{tabular}

Educação \& Realidade, Porto Alegre, v. 46, n. 1, e105371, 2021. 
(In)Eficiência Educacional sob a Perspectiva dos Gastos Públicos Desagregados

\begin{tabular}{|c|c|}
\hline AM & \begin{tabular}{|l|}
0,7792 \\
$(0,7159) \mathrm{ns}$
\end{tabular} \\
\hline AP & \begin{tabular}{|l|}
0,4629 \\
$(0,7874) n s$
\end{tabular} \\
\hline RO & \begin{tabular}{|l|}
0,0428 \\
$(0,7246) \mathrm{ns}$
\end{tabular} \\
\hline $\mathbf{R R}$ & $-0,9916$ \\
\hline $\mathrm{CE}$ & \begin{tabular}{|l|}
$-1,2327$ \\
$(0,7002)^{*}$ \\
\end{tabular} \\
\hline BA & $\begin{array}{l}0,9968 \\
(0,7019) \mathrm{ns}\end{array}$ \\
\hline MG & $-7,8708$ \\
\hline ES & \begin{tabular}{|l|}
$-2,1647$ \\
$(0,7172)^{* * *}$ \\
\end{tabular} \\
\hline SP & $\mid-9,5731$ \\
\hline RJ & $\begin{array}{l}-2,2511 \\
(0,7222)^{* * *}\end{array}$ \\
\hline RS & \begin{tabular}{|l|}
$-2,8581$ \\
$(0,6888)^{* * *}$
\end{tabular} \\
\hline PR & \begin{tabular}{|l|}
$-4,4925$ \\
$(0,6937)^{* * *}$
\end{tabular} \\
\hline SC & \begin{tabular}{|l|}
$-12,0618$ \\
$(6,6382)^{*}$
\end{tabular} \\
\hline PI & \begin{tabular}{|l|}
0,5385 \\
$(0,7055) \mathrm{ns}$
\end{tabular} \\
\hline MT & $\begin{array}{l}-1,9341 \\
(0,7089) * * *\end{array}$ \\
\hline MS & \begin{tabular}{|l|}
$-0,7061$ \\
$(0,7156) \mathrm{ns}$
\end{tabular} \\
\hline GO & \begin{tabular}{|l|}
$-3,1913$ \\
$(0,8141)^{* * *}$
\end{tabular} \\
\hline RN & \begin{tabular}{|l|}
0,6633 \\
$(0,7071) \mathrm{ns}$ \\
\end{tabular} \\
\hline PE & \begin{tabular}{|l|}
0,2986 \\
$(0,7030) \mathrm{ns}$
\end{tabular} \\
\hline TO & $\begin{array}{l}-1,5448 \\
(0,7085)^{* *}\end{array}$ \\
\hline SE & \begin{tabular}{|l|}
1,2460 \\
$(0,7095)^{*}$
\end{tabular} \\
\hline $\mathrm{AL}$ & $\begin{array}{l}1,2033 \\
(0,7120)^{*}\end{array}$ \\
\hline MA & \begin{tabular}{|l|}
0,4320 \\
$(0,7048) \mathrm{ns}$
\end{tabular} \\
\hline PA & \begin{tabular}{|l|}
1,6946 \\
$(0,7076)^{* *}$ \\
\end{tabular} \\
\hline PB & \begin{tabular}{|l|}
0,3640 \\
$(0,7058) \mathrm{ns}$
\end{tabular} \\
\hline Pequeno Porte I & \begin{tabular}{|l|}
0,0328 \\
$(0,1417) n s$
\end{tabular} \\
\hline
\end{tabular}


Bernardo; Almeida; Nascimento

\begin{tabular}{l|l}
\hline Pequeno Porte II & $\begin{array}{l}0,3990 \\
(0,1454)^{* * *}\end{array}$ \\
\hline Médio Porte & $\begin{array}{l}0,2016 \\
(0,1645) \mathrm{ns}\end{array}$ \\
\hline Constante Usigma & $\begin{array}{l}-13,9999 \\
(0,8155)^{* * *}\end{array}$ \\
\hline Constante Mu & $\begin{array}{l}0,0031 \\
(0,0016)^{* *}\end{array}$ \\
\hline Constante Vsigma & $\begin{array}{l}-4,9658 \\
(0,0191)^{* * *}\end{array}$ \\
\hline E(Sigma_u) & $0,1275^{* *}$ \\
\hline Sigma_v & $\begin{array}{l}0,0835 \\
(0,0008)^{* * *}\end{array}$ \\
\hline
\end{tabular}

Nota: em parênteses estão os erros padrão dos coeficientes. * , **, *** e ns significam, respectivamente, 90\%, 95\%, 99\% de confiança e sem significância. As dummies de controle foram Distrito Federal e Grande Porte.

Fonte: Dados da Pesquisa.

As dummies estaduais associadas aos municípios dos estados do Alagoas, Pará e Sergipe apresentaram sinal positivo, indicando aumento da ineficiência educacional. Entretanto, há contribuição negativa dos coeficientes, indicando, de fato, redução na ineficiência quando o município pertence a um dos seguintes estados: Ceará, Espírito Santo, Goiás, Mato Grosso, Paraná, Rio de Janeiro, Rio Grande do Sul, Santa Catarina ou Tocantins. Esses estados capazes de aumentar a eficiência estão, em sua maioria, em regiões de maior desenvolvimento socioeconômico, como Sul e Sudeste. Contudo, o estado do Ceará, numa das regiões menos desenvolvidas, conseguiu impulsionar a eficiência, devido às políticas educacionais implementadas para aperfeiçoar o desempenho dos alunos (Gramani, 2017).

Quanto às variáveis e sua participação na ineficiência dos gastos educacionais, das socioeconômicas, apenas os gastos com saúde per capita defasados e a infraestrutura municipal não a influenciaram. $\mathrm{O}$ acesso à energia elétrica e saneamento contribuem para o desenvolvimento escolar (Chakraborty, 2009), porém, neste estudo os dispêndios com infraestrutura foram contrários. Eles não deixam de ser importantes para a sociedade, apenas não foram significativos no processo de eficiência educacional em si.

Entretanto, os gastos com saúde e a proporção de trabalhadores formais com mão de obra qualificada aumentaram a ineficiência. Uma sociedade com maiores níveis de escolarização leva à maior transparência (Cruz et al., 2012) e, possivelmente, ao controle social. Assim, os cidadãos conseguem acompanhar se a gestão dos recursos está sendo eficiente e, por isso, esperava-se que a proporção de trabalhadores qualificados aumentaria a eficiência educacional.

Conforme Trigo (2010), a ineficiência educacional seria menor nas escolas onde as mães dos alunos obtivessem o ensino superior. Como não foi possível considerar a escolaridade das mães (Schonhaut et al., 2008), utilizou-se como proxy uma variável para indicar a escolaridade 
(In)Eficiência Educacional sob a Perspectiva dos Gastos Públicos Desagregados

da população economicamente ativa. Porém, não foi suficiente para influenciar a eficiência.

Na análise sobre saúde, não se sabe qual a proporção dos gastos que compõem o montante total, isto é, voltados para políticas de prevenção ou tratamento. Entende-se que os gastos para prevenção contribuiriam para gestão eficiente ao ter população saudável e com boas condições de saúde. Por outro lado, se os gastos são majoritariamente para tratamento de doenças, há indícios de população menos saudável. Segundo Saldiva e Veras (2018, p. 56) “[...] a garantia de saúde depende principalmente de ações efetivas de prevenção, promoção e acesso a informação seguidas pelo acesso aos serviços de saúde de qualidade, boa alimentação, moradia adequada, saneamento e segurança”.

Os fatores socioeconômicos podem ter efeitos maiores na eficiência educacional que os próprios recursos financeiros e escolares (Chakraborty, 2009). A justificativa pauta-se nas condições particulares para o desenvolvimento do aluno, pois munido de condições higiênicas adequadas, alimentação saudável e acesso à energia elétrica, cria-se um ambiente propício para melhorar a absorção cognitiva. Também, a educação não pode ser considerada isoladamente, devendo haver integração das outras dimensões (Gramani, 2017).

Outra influência deve-se à capacidade econômica dos municípios, representado pelas dummies de porte populacional, na qual os de pequeno porte II aumentaram de forma sucinta a ineficiência. Corroborando, Diel et al. (2014) e Moraes, Polizel e Crozatti (2016), os municípios com mais habitantes deveriam gerir melhor os recursos públicos para serem eficientes na geração de produtos e/ou serviços para a sociedade.

\section{Conclusões}

Os aspectos sociais (gastos com saúde e trabalhadores qualificados) foram propulsores da ineficiência educacional, sendo importantes para melhorar o sistema educacional, mas não aumentar a eficiência. Acredita-se que os gastos com saúde sejam majoritariamente compostos para políticas de tratamento das doenças, indicando não haver a locação para prevenção de doenças. Quanto à qualificação dos trabalhadores formais, maiores níveis de qualificação da população são capazes de contribuir para uma gestão eficiente, pois cidadãos mais instruídos percebem a importância do controle social.

Nenhum dos municípios analisados alcançou 100\% de eficiência, dada a ineficiência técnica média de 12,75\%. Entretanto, os mais eficientes apresentaram como característica comum maiores destinações de recursos financeiros a aspectos sociais, salas de aula com menor número de alunos, proporcionando maior contato com professores, e, principalmente, ter cerca de $90 \%$ dos alunos matriculados na série coerente à idade, isto é, com baixo percentual de defasagens no processo educacional. Em contrapartida, os que possuem mais dificuldades para gerir eficientemente os recursos em educação, estão localizados 
no Norte e Nordeste, com porte populacional médio e baixos investimentos em saúde e infraestrutura.

Devido às diferenças interestaduais e inter-regionais de eficiência percebidas, é importante que seja feita a gestão eficiente sem desconsiderar o bem-estar social e as especificidades locais, pois a variação da eficiência acompanha a condição socioeconômica dos municípios/ estados. Ademais, o fato de os mais ineficientes estarem em regiões menos desenvolvidas reforça a importância de políticas para equalizar as condições de acesso ao ensino com qualidade e eficiência.

Apesar do resultado contrário ao esperado, reforça-se a importância da remuneração dos profissionais da educação, valorização salarial e plano de carreira. Isto, porque considera-se que as políticas educacionais promovidas não surtem efeitos desejados no mesmo período de sua implementação, sendo necessário avaliar seus efeitos e complexidades em períodos futuros.

Das limitações deste estudo, a principal foi a ausência de dados para um período de tempo maior, não sendo possível considerar a defasagem anual das variáveis financeiras da educação. Para pesquisas futuras, sugere-se abordar mais períodos de tempo e outros aspectos para caracterizar o ambiente escolar e municipal, seja no âmbito de aluno/ escola ou de aspectos institucionais e de gestão.

Recebido em 14 de julho de 2020 Aprovado em 4 de janeiro de 2021

\section{Referências}

AGUIAR, Neuma. Patriarcado, Sociedade e Patrimonialismo. Sociedade e Estado, Brasília, v. 15, n. 2, 2000.

AIGNER, Dennis; LOVELL, Charles Albert Knox; SCHMIDT, Peter. Formulation and Estimation of Stochastic Frontier Production Function Models. Journal of Econometrics, v. 6, p. 21-37, 1997.

ALMEIDA, Carlos Wellington Leite de. Fiscalização Contratual: 'calcanhar de aquiles' da execução dos contratos administrativos. Revista do TCU, v. 114, p. 53-62, 2009.

ANDRADE, Rita de. Teoria do Capital Humano e a Qualidade da Educação nos Estados Brasileiros. 2010. Trabalho de Conclusão de Curso (Graduação em Economia) - Universidade Federal do Rio Grande do Sul, Porto Alegre, 2010.

BATISTA, João Luís. Verossimilhança e Máxima Verossimilhança. Escola Superior de Agricultura 'Luiz de Queiroz', Universidade de São Paulo, 2009.

BATTESE, George ; COELLI, Timothy. A Model for Technical Inefficiency Effects in a Stochastic Frontier Production Function for Panel Data. Empirical Economics, v. 20, p. 325-332, 1995.

BENTO, Paula Marisa Gonçalves Martins. Fronteira Estocástica de Produção de Conhecimento: Inovação e Desenvolvimento Sustentável. 2014. 132 f. Dissertação (Mestrado), Faculdade de Matemática, Universidade de Évora, Évora, 2014. 
(In)Eficiência Educacional sob a Perspectiva dos Gastos Públicos Desagregados

BERNARDO, Joyce Santana; ALMEIDA, Fernanda Maria de; NASCIMENTO, Ana Carolina Campana. Qualidade Geral da Educação Municipal e as Influências dos Gastos Públicos. Arquivos Analíticos de Políticas Educativas, v. 28, n. 23, 2020.

BRASIL. Constituição da República Federativa do Brasil. Diário Oficial da União, Brasília, 1988.

BRASIL. Lei no 9.394, de 20 de dezembro de 1996.Estabelece as diretrizes e bases da educação nacional. Diário Oficial da União, Brasília, 1996. Disponível em: <http://www.planalto.gov.br/ccivil_03/leis/L9394.htm>. Acesso em: 02 jun. 2019.

BRASIL. Lei Complementar no101, de 4 de maio de 2000. Estabelece normas de finanças públicas voltadas para a responsabilidade na gestão fiscal e dá outras providências. Diário Oficial da União, Brasília, 2000. Disponível em: <http:// www.planalto.gov.br/ccivil_03/LEIS/LCP/Lcp101.htm>. Acesso em: 02 jun. 2019.

CABRAL, Antônio; SILVA, Claudia Luciene de Melo; SILVA, Lamara Fabia Lucena. Teoria do Capital Humano, Educação, Desenvolvimento Econômico e Suas Implicações na Formação de Professores. Revista Principia, João Pessoa, n. 32, 2016.

CARVALHO, Márcia Marques de; WALTENBERG, Fábio Domingues. Desigualdade de Oportunidades no Acesso ao Ensino Superior no Brasil: uma comparação entre 2003 e 2013. Economia Aplicada, Ribeirão Preto, v. 19, n. 2, p. 369-396, 2015.

CHAKRABORTY, Kalyan. Efficiency in Public Education - the role of socioeconomic variables. Research in Applied Economics, v. 1, n. 1, 2009.

COLEMAN, James Samuel. et al. Equality of Educational Opportunity. Washington: Government Printing Office, 1966.

CRUZ, Cláudia Ferreira et al. Transparência da Gestão Pública Municipal: um estudo a partir dos portais eletrônicos dos maiores municípios brasileiros. Revista de Administração Pública, Rio de Janeiro, v. 46, n. 1, p. 153-76, 2012.

CUNHA, Luana Francieli da. A Importância de uma Alimentação Adequada na Educação Infantil. Monografia (Pos-Graduação em Ensino das Ciencias), Universidade Tecnológica Federal do Paraná (UTFPR), Medianeira, 2014.

DALCHIAVON, Eloisa Carla; MELO, Cármen Ozana de. Eficiência dos Gastos Públicos em Educação, Saúde e Trabalho para o Desenvolvimento dos Municípios Paranaenses. In: CONGRESSO NACIONAL DE PESQUISA EM CIÊNCIAS SOCIAIS APLICADAS, 5., 2016, Francisco Beltrão. Anais... Francisco Beltrão, 2016. P. 38-49.

DELGADO, Victor Maia Senna; MACHADO, Ana Flávia. Eficiência das Escolas Públicas Estaduais de Minas Gerais. Pesquisa e Planejamento Econômico, v. 37, n. 3, 2008.

DIEL, Elisandra Henn et al. Desempenho De Municípios Brasileiros em Relação à Estratégia de Investimento Público em Educação. Desenvolvimento em Questão, v. 12, n. 26, p.79-107, 2014.

FAGERBERG, Jan; SRHOLEC, Martin; VERSPAGEN, Bart. Innovation and Economic Development. Handbook of the Economics of Innovation, v. 2, p. 833872, 2009.

FARIA, Flavia Peixoto; JANNUZZI, Paulo de Martino; SILVA, Silvano José da. Eficiência dos Gastos Municipais em Saúde e Educação: uma investigação através 
Bernardo; Almeida; Nascimento

da análise envoltória no estado do Rio de Janeiro. Revista de Administração Pública, v. 42, n. 1, p. 155-177, 2008.

FERREIRA, Carlos Maurício de Carvalho; GOMES, Adriano Provezano. Introdução à Análise Envoltória de Dados: teoria, modelos e aplicações. Viçosa, Minas Gerais: Editora UFV, 2012.

FLORES, Isabel. Modelling Efficiency in Education: how are european countries spending their budgets and what relation between money and performance. Sociologia, Problemas e Práticas, v. 83, 2017.

GRAMANI, Maria Cristina. Análise dos Determinantes de Eficiência Educacional do Estado do Ceará. Ensaio: avaliação e políticas públicas em educação, Rio de Janeiro, v. 25, n. 95, p. 507-526, 2017.

GROSSKOPF, Shawna; HAYES, Kathy; TAYLOR, Lori. Efficiency in Education: Research and Implications. Applied Economic Perspectives and Policy, v. 36, n. 2, p. 175-210, 2014a.

GROSSKOPF, Shawna; HAYES, Kathy; TAYLOR, Lori. Applied Efficiency Analysis in Education. Economics and Business Letters, v. 3, n. 1, p. 19-26, 2014b.

IDE, Maria Helena de Souza; ROTTA JUNIOR, César. Educação para o Desenvolvimento: a Teoria do Capital Humano no Brasil nas décadas de 1950 e 1960. Revista Brasileira de Estudos Jurídicos, v. 8, n. 2, 2013.

JOHNES, Jill; PORTELA, Maria; THANASSOULIS, Emmanuel. Efficiency in Education. Journal of the Operational Research Society, v. 68, p. 331-338, 2017.

LEVIN, Henry; JAMISON, Dean; RADNER, Roy. Concepts of Economic Efficiency and Educational Production. In: FROOMKIM, Joseph; JAMISON, Dean; RADNER, Roy. Education as an Industry. NBER, 1976. P. 149-198.

MARGINSON, Simon. Productivity and Efficiency in Education. Australian Journal of Education, v. 35, 1991.

MASI, Barbara. A Ticket to Ride: The unintended consequences of school transport subsidies. Economics of Education Review, v. 63, 2018.

MATTOS, Enlinson; TERRA, Rafael. Conceitos Sobre Eficiência. In: BOUERI, Rogério; ROCHA, Fabiana; RODOPOULOS, Fabiana (Org.). Avaliação da Qualidade do Gasto Público e Mensuração da Eficiência. Brasília: Secretaria do Tesouro Nacional, 2015. P. 463.

MORAES, Vinicius Macedo de; POLIZEL, Mayra Francisco; CROZATTI, Jaime. Eficiência Dos Gastos Municipais Com a Educação Fundamental: uma análise dos municípios paulistas no ano de 2013. In: CONGRESSO BRASILEIRO DE CUSTOS, 23., 2016, Porto de Galinhas. Anais... Porto de Galinhas, 2016. P. 23-43.

MORAIS, Reinaldo Carvalho de. Eficiência do Gasto Público em Educação Fundamental nas Prefeituras Mineiras: Uma abordagem via análise envoltória de dados. 2009. 78 f. Dissertação (Mestrado), Fundação João Pinheiro, Belo Horizonte, 2009 .

PACHECO, Regina Silvia. A Agenda da Nova Gestão Pública. In: ABRUCIO, Fernando; LOUREIRO, Maria Rita; PACHECO, Regina Silvia (Org.). Burocracia e Política no Brasil: desafio para o estado democrático no século XXI. led. Rio de Janeiro: Editora da Fundação Getúlio Vargas, 1, 2010. P. 171-196.

PENKOVA, Evgenia; VALKOV, Alexander. The Quality of Education: an economic view. Journal of Process Management - new technologies, international, v. 3, n. 3, p. 26-33, 2015.

Educação \& Realidade, Porto Alegre, v. 46, n. 1, e105371, 2021. 
(In)Eficiência Educacional sob a Perspectiva dos Gastos Públicos Desagregados

PINTOCO, Vanessa Moreira. Visão do Professor Sobre o Número de Alunos por Turma: uma contribuição para a melhoria da qualidade da educação. 2017. 186 f. Dissertação (Mestrado em Educação). Escola Superior de Educação, Porto, 2017.

PIRES, Jorge Oliveira. Produtividade das Nações: uma abordagem de fronteiras estocásticas. 2004. 143 f. Tese (Doutorado), Fundação Getúlio Vargas, São Paulo, Brasil, 2004.

PITT, Mark; LEE, Lung-Fei. The Measurement and Sources of Technical Inefficiency in the Indonesian Weaving Industry. Journal of Development Economics, v. 9, 1981.

RAMOS, Flavia Pascoal; SANTOS, Ligia Amparo da Silva; REIS, Amélia Borba Costa. Educação Alimentar e Nutricional em Escolares: uma revisão de literatura. Caderno Saúde Pública, Rio de Janeiro, v. 29, n. 11, p. 2147-2161, 2013.

RECUERO, Laura Heras; OLABERRÍA, Eduardo. Public Spending in Education and Students' Performance in Colombia. OECD, Economics Department Working Papers, n. 1460, 2018.

SALDIVA, Paulo Hilário Nascimento; VERAS, Mariana. Gastos Públicos com Saúde: breve histórico, situação atual e perspectivas futuras. Estudos Avançados, v. 32, n. 92, 2018.

SAVIAN, Mayá Patricia Gemelli; BEZERRA, Fernanda Mendes. Análise de Eficiência dos Gastos Públicos com Educação no Ensino Fundamental no Estado do Paraná. Economia \& Região, v. 1, n. 1, p. 26-47, 2013.

SCHMIDT, Peter; SICKLES, Robin. Production Frontiers and Panel Data. Journal of Business and Economic Statistics, v. 2, n. 4, p. 367-374, 1984.

SCHONHAUT, Luisa et al. Lenguaje e Inteligencia de Preescolares: análisis de su relación y factores asociados. Revista Chilena de Pediatría, Santiago, v. 79, n. 6, p. 600-606, 2008.

SCHUSTER, Herivélton Antônio; ZONATTO, Vinicius. Evidências da Eficiência de Gastos Públicos na Alocação dos Recursos Destinados ao Ensino Fundamental nos Estados Brasileiros. Contextus Revista Contemporânea de Economia e Gestão, v. 15, n. 2, 2017.

SEABRA, Sérgio Nogueira. A Nova Administração Pública e Mudanças Organizacionais. Revista de Administração Pública, v. 35, n. 4, p. 19-43, 2001.

SEDIYAMA, Gislaine Aparecida Santana; AQUINO, André Carlos Busanelli de; LOPES, Gabriela Brandão. A Difusão das Mudanças na Contabilidade Pública em Municípios. Revista Contabilidade Vista e Revista, v. 28, n. 2, 2017.

SILVA, Nelson do Valle; HASENBALG, Carlos. Recursos Familiares e Transições Educacionais. Cadernos de Saúde Pública [online], v. 18, 2002.

SOUSA JUNIOR, Wilson Rodrigues de. A Criança e o Consumo na Escola. 2009. 103 f. Dissertação (Mestrado), Universidade Federal do Espírito Santo, Vitoria, 2009.

TODARO, Michael; SMITH, Stephen. Economic Development. $11^{\text {th }}$ edition. Pearson, 2012.

TRIGO, Priscila Pacheco. Avaliação da Eficiência Técnica no Ensino Básico Brasileiro. 2010. 84 f. Dissertação (Mestrado em Educação) - Universidade de São Paulo, Ribeirão Preto, 2010.

URWICK, James; JUNAIDU, Sanusi Usman. The Effects of School Physical Facilities on the Processes of Education: a qualitative study of nigerian primary 
Bernardo; Almeida; Nascimento

schools. International Journal of Educational Development, v. 11, n. 1, p. 19-29, 1991.

VIEIRA, Fabiola Sulpino. Evolução do Gasto com Medicamentos do Sistema Único de Saúde no Período de 2010 a 2016. Texto para Discussão. Instituto de Pesquisa Econômica Aplicada, 2018.

ZOGHBI, Ana Carolina et al. Uma Análise da Eficiência nos Gastos em Educação Fundamental para os Municípios Paulistas. Planejamento e Políticas Públicas, v. 36, p. 9-61, 2011

Joyce Santana Bernardo é Mestre em Administração, com ênfase em Administração Pública e graduada em Ciências Contábeis.

ORCID: http://orcid.org/0000-0003-0014-8964

E-mail: joycebernardoccoufv@gmail.com

Fernanda Maria de Almeida é Professora Doutora Adjunta do Departamento de Administração e Contabilidade da Universidade Federal de Viçosa. ORCID: http://orcid.org/0000-0001-9132-1552

E-mail: fernanda.almeida@ufv.br

Ana Carolina Campana Nascimento é Professora Doutora Adjunta do Departamento de Estatística da Universidade Federal de Viçosa.

ORCID: http://orcid.org/0000-0002-6985-1490

E-mail: ana.campana@ufv.br

Editora-responsável: Beatriz Vargas Dorneles

Este é um artigo de acesso aberto distribuído sob os termos de uma Licença Creative Commons Atribuição 4.0 Internacional. Disponível em: <http:// creativecommons.org/licenses/by/4.0>. 